\title{
A ring test of in vitro neutral detergent fiber digestibility: Analytical variability and sample ranking ${ }^{1}$
}

\author{
M. B. Hall ${ }^{2}$ and D. R. Mertens \\ US Dairy Forage Research Center, USDA-Agricultural Research Service, Madison, WI 53706
}

\begin{abstract}
In vitro neutral detergent fiber (NDF) digestibility (NDFD) is an empirical measurement of fiber fermentability by rumen microbes. Variation is inherent in all assays and may be increased as multiple steps or differing procedures are used to assess an empirical measure. The main objective of this study was to evaluate variability within and among laboratories of 30-h NDFD values analyzed in repeated runs. Subsamples of alfalfa $(\mathrm{n}=4)$, corn forage $(\mathrm{n}=5)$, and grass $(\mathrm{n}=5)$ ground to pass a 6 - $\mathrm{mm}$ screen passed a test for homogeneity. The 14 samples were sent to 10 laboratories on 3 occasions over 12 mo. Laboratories ground the samples and ran 1 to 3 replicates of each sample within fermentation run and analyzed 2 or 3 sets of samples. Laboratories used 1 of 2 NDFD procedures: 8 labs used procedures related to the 1970 Goering and Van Soest (GVS) procedure using fermentation vessels or filter bags, and 2 used a procedure with preincubated inoculum (PInc). Means and standard deviations (SD) of sample replicates within run within laboratory (lab) were evaluated with a statistical model that included lab, run within lab, sample, and lab $\times$ sample interaction as factors. All factors affected mean values for $30-h$ NDFD. The lab $\times$ sample effect suggests against a simple lab bias in mean values. The SD ranged from 0.49 to $3.37 \%$ NDFD and were influenced by lab and run within lab. The GVS procedure gave greater NDFD values than PInc, with an average difference across all samples of $17 \%$ NDFD. Because of the differences between GVS and PInc, we recommend using results in contexts appropriate to each procedure. The $95 \%$ probability limits for within-lab repeatability and among-lab reproducibility for GVS mean values were 10.2 and $13.4 \%$, respectively. These percentages describe the span of the range around the mean into which $95 \%$ of analytical results for a
\end{abstract}

Received August 4, 2011.

Accepted November 26, 2011.

${ }^{1}$ Mention of any trademark or proprietary product in this paper does not constitute a guarantee or warranty of the product by the USDA or the Agricultural Research Service and does not imply its approval to the exclusion of other products that also may be suitable.

${ }^{2}$ Corresponding author: marybeth.hall@ars.usda.gov sample fall for values generated within a lab and among labs. This degree of precision was supported in that the average maximum difference between samples that were not declared different by means separation was $4.4 \%$ NDFD. Although the values did not have great precision, GVS labs were able to reliably rank sample data in order of 30-h NDFD (Spearman correlation coefficient $=0.93$ ) with $80 \%$ of the rankings correct or off by only 1 ranking. A relative ranking system for NDFD could reduce the effect of within- and among-lab variation in numeric values. Such a system could give a more accurate portrayal of the comparative values of samples than current numeric values imply.

Key words: fiber, digestibility, rumen, in vitro

\section{INTRODUCTION}

In vitro methods that use ruminal microbial fermentation to assess feed digestibility have been in use for decades (Tilley and Terry, 1963; Goering and Van Soest, 1970). The results of these empirical assays can correlate with digestibility of the feedstuffs in animals (Tilley and Terry, 1963) and be used to predict animal performance (Oba and Allen, 1999). In vitro NDF digestibility (NDFD) values have been used in dietary evaluation or formulation programs to describe the potential digestible nutrient contribution of a given feedstuff to the diet (e.g., 48-h in vitro NDFD; NRC, 2001). In the field, nutritionists have also used relative changes in the NDFD of a feed to qualitatively modify the energy values of feeds [R. Prange (Land O' Lakes Purina LLC, Oregon, WI) and H. Ballantine (HTB Consulting LLC, Hiram, GA); personal communication]. The greater suitability for use as a specific number or as a relative value depends in part upon the precision of the NDFD assay results.

In vitro measurement of NDF digestibility is accomplished with empirical, multiple-step, gravimetric bioassays. The multiple steps involved once the sample arrives at the laboratory include drying and grinding of sample; subsampling for DM, NDF, and NDFD analyses; fermentation of a subsample; and analysis of fermentation residue and original sample for NDF. Each step contributes to the normal variation in the 
analytical values; protocol variations within and among laboratories will typically increase the variability of values. Differences in method type and fineness of grind (Wilman and Adesogan, 2000; Damiran et al., 2008), and sample weight used (Damiran et al., 2008) can alter in vitro digestibility results. Additionally, differences in composition of diets offered to inoculum donors have been shown to affect in vitro digestibility of fiber (Jung and Varel, 1988) and DM (Soder, 2005). Modifications such as evaluating NDFD at times earlier than $48 \mathrm{~h}$ to differentiate between more rapidly or slowly fermenting feeds can increase the likelihood that techniques that affect the efficacy of the microorganisms and progress of the fermentation will increase variability of the results. With numerous sources of variation, and given the perspective that to measure a $1 \%$ NDFD change, postfermentation changes of 0.5 to $3 \mathrm{mg}$ in the weight of NDF residue must be detected, what degree of precision is presently being achieved with fiber digestibility assays? Studies have reported comparisons of methods, but no extensive comparison of values generated within and among labs exists to provide more comprehensive estimates of precision. The objective of this study was to evaluate the precision of forage fiber digestibility values generated within and among laboratories and the ability of laboratories to rank samples by NDFD value.

\section{MATERIALS AND METHODS}

\section{Samples}

Fourteen samples representing an array of maturities and types within 3 forage types were collected (Table 1). An attempt was made to include samples that were likely to have very high or very low NDFD within each forage type. Wet samples were dried at $55^{\circ} \mathrm{C}$ in a forced-air oven before grinding. All samples were ground to pass the 6-mm screen of a Wiley mill (Arthur H. Thomas Co., Philadelphia, PA) and subsampled using a 24-place Sepor rotary sample splitter (Sepor Inc., Wilmington, CA). Subsamples (50 g air dry) were sealed in individual packets labeled with the numeric identity assigned to the forage sample. Three separate portions from each of 6 packets from each of the 14 samples were scanned by near-infrared reflectance spectroscopy (NIRS) to provide data to test the homogeneity of samples. The NIRS scans were not used to determine composition of subsamples, per se. The NIRS readings are very repeatable and were used to detect differences between samples. By scanning to assess $\mathrm{DM}, \mathrm{CP}, \mathrm{NDF}$, and $\mathrm{ADF}$, which have spectra that fall in different regions of the overall range of spectra, subsamples of a forage could be nondestructively, rapidly, and repeatedly tested to determine whether they were similar on the basis of similarity or dissimilarity of results based on the spectra.

\section{Participating Laboratories}

Nine feed analysis laboratories (labs), representing 5 commercial and 4 research labs, elected to participate in the ring test. Labs were assured confidentiality regarding their identities and participation in the study. Labs used different in vitro fermentation and NDF measurement procedures (Table 2) and used differing numbers of inoculums donors offered different diets (Table 3). One research laboratory ran 2 different in vitro procedures; each procedure was listed as a separate lab to give a total of 10 labs. Eight of the labs used a variant of the Goering and Van Soest (1970) procedure (GVS) and 2 labs used a procedure in which the inoculum was preincubated with carbohydrate and protein before inoculation of fermentation vessels (PInc; Goeser et al., 2009; Goeser and Combs, 2009). Laboratory 4 adjusted NDFD values based on the results of control samples fermented within a run. Laboratory 1 used sealable tubes incubated in an orbital shaker-incubator (Innova 40, New Brunswick Scientific, Edison, NJ) with tubes set horizontally in racks, parallel to the motion of the shaker and agitated at $160 \mathrm{rpm}$.

\section{Ring Test}

Laboratories were sent sets of the 14 forage samples 3 times over the course of a year to allow for 3 fermentation runs per lab. A new set of samples was sent to labs when the results from the previous analytical run had been received, so analytical runs on different sets of samples were conducted on different days. Participants were to grind the samples and analyze them in duplicate for NDF and 30-h NDFD according to their usual procedures, and to provide the calculated results of the individually analyzed replicates for NDF and NDFD, as well as the raw data used in the calculations. Laboratories were also invited to contribute 48-h NDFD data if they were willing to conduct that additional analysis. The NDFD values as a percentage of NDF in the sample were calculated as $[1-(\mathrm{g}$ of residual NDF after fermentation/g of sample NDF) $] \times 100$. The digested NDF that disappeared during fermentation expressed as a percentage of sample DM (dNDF) was calculated as (g of sample NDF - g of residual NDF after fermentation)/g of sample DM, with both NDF values and $\mathrm{dNDF}$ expressed as a percentage of original sample DM.

Data from the labs were evaluated for accuracy of calculations. If a lab provided 3 or more replicates for a sample in a fermentation run, the data were evaluated 
Table 1. Forage samples used in the ring test

\begin{tabular}{|c|c|c|c|c|c|c|c|c|}
\hline Sample ID & Forage type & DM, \% & $\begin{array}{l}\text { Ash, } \% \\
\text { of DM }\end{array}$ & $\begin{array}{l}\mathrm{CP}, \% \\
\text { of DM }\end{array}$ & $\begin{array}{l}\text { aNDF, }{ }^{1} \% \\
\text { of DM }\end{array}$ & $\begin{array}{l}\text { aNDFOM, }{ }^{1} \\
\% \text { of DM }\end{array}$ & $\begin{array}{c}\text { GVS mean } \\
\text { 30-h NDFD, }{ }^{2} \\
\%\end{array}$ & $\begin{array}{c}\text { PInc mean } \\
\text { 30-h NDFD, }{ }^{2} \\
\%\end{array}$ \\
\hline Alfalfa & Medicago sativa L. & & & & & & & \\
\hline 11 & Alfalfa haycrop silage & 90.5 & 9.74 & 22.28 & 37.7 & 36.5 & 46.5 & 31.9 \\
\hline 12 & Alfalfa hay & 92.5 & 9.36 & 19.79 & 38.1 & 36.8 & 39.8 & 29.8 \\
\hline 7 & Alfalfa hay, mature & 92.7 & 8.30 & 14.52 & 43.8 & 43.1 & 39.1 & 26.9 \\
\hline 6 & Tropical corn silage & 91.8 & 4.23 & 9.28 & 40.1 & 39.7 & 51.4 & 24.4 \\
\hline 9 & Conventional corn silage & 92.2 & 3.95 & 5.85 & 36.9 & 36.1 & 48.1 & 22.4 \\
\hline 10 & Ensiled corn stover & 93.1 & 11.53 & 3.83 & 70.5 & 63.9 & 43.9 & 28.4 \\
\hline \multicolumn{9}{|l|}{ Grass } \\
\hline 3 & $\begin{array}{l}\text { Orchardgrass, } \\
\text { Dactylis glomerata L. }\end{array}$ & 93.2 & 11.11 & 18.16 & 42.9 & 41.7 & 73.9 & 60.3 \\
\hline 14 & Mixed temperate grass hay & 93.2 & 7.74 & 8.27 & 64.1 & 61.3 & 33.6 & 21.0 \\
\hline
\end{tabular}

${ }^{1}$ aNDF $=$ NDF analyzed using heat-stable $\alpha$-amylase and Na sulfite, with-ash basis; aNDFOM = aNDF on an ash-free basis.

${ }^{2}$ GVS = Goering and Van Soest (1970) method; PInc = using preincubated inoculum (Goeser et al., 2009, Goeser and Combs, 2009); NDFD = NDF digestibility values (NDF fermented as \% of sample NDF). Values are arithmetic means.

for outliers using the Dixon Q test (Dean and Dixon, 1951; Rorabacher, 1991); 4 outliers were found in 30-h NDFD data and 7 in the 48-h NDFD data. Data were analyzed with outliers excluded. Removal of outliers is justified in that labs would exclude detected deviant values before reporting results. The sample replicate means and standard deviations used in the statistical analyses were calculated for each sample in each fermentation run in each lab.

The ability of the labs to rank samples based on 30-h NDFD was evaluated. The ranking exercise was applied only to GVS data because of the greater number of values for that set of procedures, to keep within method type, and because inclusion of PInc gave lower Spearman correlation coefficients; PInc differed from GVS in overall ranking of one of the corn forage samples, although grass and alfalfa samples were ranked similarly (Table 1). Mean values for samples were ranked from least to greatest 30-h NDFD within a fermentation run within a lab. The ranking was applied both within forage type and across all samples. An average rank for a sample was determined based on the rank of the grand mean calculated from all of the 30-h NDFD values for that sample from all GVS labs and runs. The absolute differences between ranks and the corresponding average ranks were calculated.

\section{Statistics}

Homogeneity of samples in individual packets was tested using NIRS-predicted values for CP, NDF, and
ADF for each sample. Data were evaluated with ANOVA for a 2-way classification (samples with replicates) to determine whether subsamples of each forage sample differed. By this analysis, the subsamples did not differ $(P>0.05)$.

Two separate sets of statistical analyses were performed on data provided by the labs. One described the significance of effects of lab, analytical run (a descriptor of analytical replicate for analyses run on separate days), and sample. The other statistical evaluation assessed the precision of the data generated within and among labs.

Sample means and standard deviations calculated for samples in each run in each lab were analyzed with a model that contained lab, run within lab, sample, and the lab $\times$ sample interaction. "Run" described the analysis of a single set of subsampled materials that was sent to a lab; a lab would have a maximum of 3 runs if they chose to analyze all 3 sets of subsamples they were sent over the course of the study. All labs completed a given run within 2 wk or several months after they received a set of samples, so time-related aspects of runs were not similar across labs. "Run within lab" rather than "run" was used to evaluate analytical variation of assays performed on different days within labs to assess the performance of labs in executing replicated analytical runs rather than making a global assessment of all analytical runs in all labs. No terms were used as random variables in order to determine the significance of all terms. Bonferroni mean separa- 
Table 2. Methods used by participating laboratories (lab; note: lab 5 was originally included but later declined to participate and no lab 5 data were included in the study)

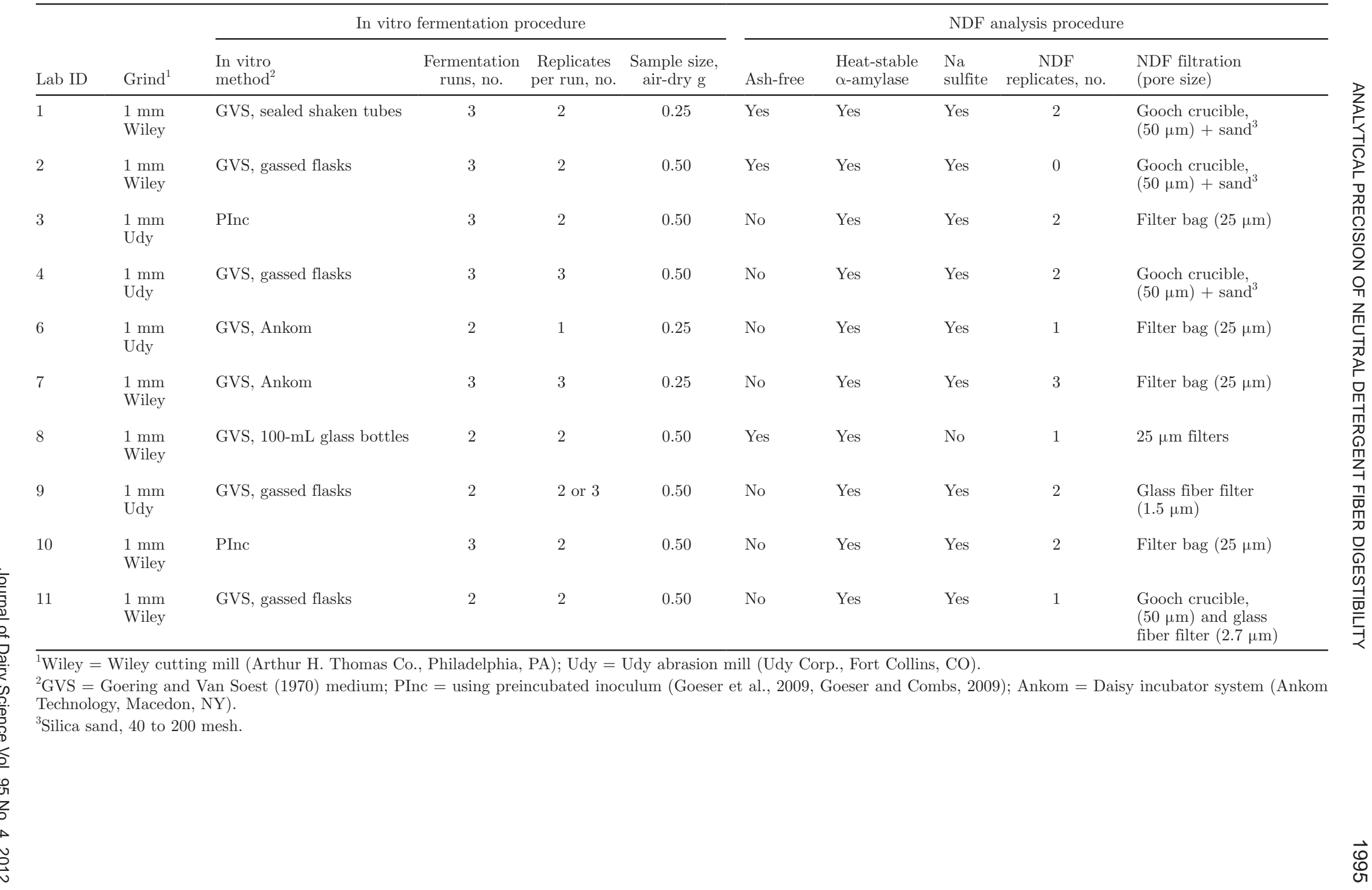


Table 3. Inoculum donors and diets offered

\begin{tabular}{|c|c|c|c|c|}
\hline Laboratory ID & Inoculum donors & Forage & $\begin{array}{l}\text { Forage, } \\
\% \text { of diet DM }\end{array}$ & Concentrate components \\
\hline 1 & 4 lactating cows & $\begin{array}{l}\text { Corn silage } \\
\text { Alfalfa silage }\end{array}$ & 60 & $\begin{array}{l}\text { High moisture corn } \\
\text { Soybean meal }\end{array}$ \\
\hline 2 & 4 lactating cows & $\begin{array}{l}\text { Corn silage } \\
\text { Alfalfa silage }\end{array}$ & 60 & $\begin{array}{l}\text { High moisture corn } \\
\text { Soybean meal }\end{array}$ \\
\hline 3 & 2 lactating cows & $\begin{array}{l}\text { Corn silage } \\
\text { Alfalfa haylage } \\
\text { Alfalfa hay } \\
\text { Wheat straw }\end{array}$ & 94 & $\begin{array}{l}\text { Distillers grains } \\
\text { Dry ground corn } \\
\text { Soybean meal }\end{array}$ \\
\hline 4 & 3 steers & $\begin{array}{l}\text { Corn silage } \\
\text { Haylage } \\
\text { Dry hay }\end{array}$ & 100 & None \\
\hline 6 & 1-2 lactating cows & $\begin{array}{l}\text { Corn silage } \\
\text { Alfalfa silage }\end{array}$ & 55 & $\begin{array}{l}\text { High moisture corn } \\
\text { Citrus pulp } \\
\text { Soybean meal } \\
\text { Canola meal }\end{array}$ \\
\hline 8 & 2 nonlactating cows & Not provided & Not provided & Not provided \\
\hline 9 & 3 lactating cows & $\begin{array}{l}\text { Corn silage } \\
\text { Legume/triticale silage }\end{array}$ & 50 & $\begin{array}{l}\text { High moisture corn } \\
\text { Bakery/cookie meal } \\
\text { Soybean meal } \\
\text { Heat-treated soybean meal } \\
\text { Citrus pulp }\end{array}$ \\
\hline 10 & 2 lactating cows & $\begin{array}{l}\text { Corn silage } \\
\text { Alfalfa haylage } \\
\text { Alfalfa hay } \\
\text { Wheat straw }\end{array}$ & 94 & $\begin{array}{l}\text { Distillers grains } \\
\text { Dry ground corn } \\
\text { Soybean meal }\end{array}$ \\
\hline 11 & $2-3$ dry cows & $\begin{array}{l}\text { Legume/grass hay } \\
\text { Legume/grass silage } \\
\text { Corn silage }\end{array}$ & 100 & None \\
\hline
\end{tabular}

tion was used to detect differences between labs, and to determine within lab the smallest numeric difference between values for NDFD or dNDF for samples that were designated as different $(P<0.05)$.

As measures of precision, the $95 \%$ probability limits for repeatability and reproducibility for 30-h NDFD were calculated for each of the 14 samples according to AOAC methods (AOAC International, 2002). The AOAC statistical methods were chosen as the most well established and purposefully designed for evaluation of analytical precision within and across laboratories. The 95\% probability limit describes the range in which $95 \%$ of analytical values for a sample are likely to fall. "Repeatability" refers to the values as replicated within a single lab, and "reproducibility" refers to values replicated across labs. The results of GVS and PInc procedures were sufficiently different that PInc data were omitted from this evaluation. Individual replicate values from all runs from labs using GVS methods were used, exclusive of outliers. Although the AOAC calculations were designed to evaluate data generated by laboratories in a single analytical run, entry of all data from all runs by lab was recommended as an approach to assessing overall variability of the data (P. Wehling, Chair, Statistics Committee, AOAC International, Gaithersburg, MD, personal commun.). The $95 \%$ probability limit results were analyzed with a model containing forage type as the sole factor and with orthogonal contrasts comparing corn forage results versus alfalfa and grass, and alfalfa versus grass. The AOAC evaluation was not applied to measures other than 30-h NDFD, because removal of labs giving ash-free values (as for NDF and dNDF) or having too few labs (PInc and 48-h fermentation values) gave fewer than the 8 labs needed to apply the procedure.

Paired $t$-tests were performed to compare equivalence of standard deviations for 30-h and 48-h NDFD and coefficients of variation (SD/mean) for 30-h NDFD and dNDF. Spearman correlation tests for the ranking of samples by labs versus the average ranking for the 
samples were performed for each forage type and across all samples and applied only to data from labs reporting GVS methods. Statistical analyses were performed using the MIXED procedure of SAS (release 8.0, SAS Institute Inc., Cary, NC) unless otherwise indicated. Significance was declared at $P<0.05$ and tendency from $0.05 \leq P \leq 0.15$.

\section{RESULTS AND DISCUSSION}

An empirical assay defines the analyte it measures. For example, NDF does not exist as an independent entity but is a fraction measured with an NDF method. Procedures for NDF, NDFD, and dNDF as described in this paper are all empirical assays. Because the empirical assay defines the analyte, variations in the method protocol are likely to change measured values on identical subsamples beyond what may be predicted from expected analytical variation (Damiran et al., 2008). Particularly if different versions of a procedure exist, or if it is not possible to avoid differences in some aspects of how the assay is executed, analytical results will likely differ to some greater or lesser extent and must be considered in that context.

Many portions of the methods used differed among labs. The labs in this ring test ground samples using abrasion or cutting mills, which give different sample particle sizes even at the same screen size (Mertens, 1991). Most but not all labs used heat-stable $\alpha$-amylase and Na sulfite in the NDF analyses and reported values on a with-ash basis; differences in NDF technique alter the analytical values (Mertens, 2002). Two distinct fermentation methods, GVS and PInc, were used, and 4 modifications were applied within GVS methods. Inoculum source varied in type and number of animals used, diets of the animals, and in preparation method. Animal species used as the inoculum source has been shown to affect rate of fermentation, whereas proportions of solid and liquid phases of rumen contents used can alter in vitro digestibility (Bueno et al., 2005). Sample weight used and pore size of filtration media differed. It is not surprising that differences were found in the analytical results among labs. What was interesting was that GVS labs were able to rank samples similarly, despite the potential for analytical differences based on diversity of the methods used.

\section{NDF}

The NDF analysis results for unfermented samples differed by lab, run within lab, sample, and lab $\times$ sample interaction (Table 4; Supplemental Tables S1 and S2, available online at http://www.journalofdairyscience.org/). The lab $\times$ sample effect suggests against a simple lab bias. One lab did not use Na sulfite (lab 8) and 2 labs reported values on an ash-free basis (labs 1 and 8). However, more differences were observed among labs than could be ascribed to those factors (see means separations, Table 4). The average values by lab across all analyses of all samples showed a range of 46.7 to $54.9 \%$ for NDF with ash values.

The standard deviations of sample replicates for NDF determination differed with the effects of lab, run within lab, and lab $\times$ sample interaction, but were not affected by sample (Table 4; Supplemental Tables S1 and S2, available online at http://www.journalofdairyscience.org/). All but one lab had standard deviations $<1.0 \%$ of $\mathrm{DM}$, with values for labs $1,4,7,9$, and 10 falling within or near the within-lab repeatability reported for NDF analyses (Mertens, 2002). The small standard deviations for sample replicates indicate good repeatability within lab for this method.

\section{0-h NDFD}

The 30-h NDFD values were affected by lab, run within lab, sample, and lab $\times$ sample interaction for comparisons of all labs (Table 4; Supplemental Tables S2 and S3, available online at http://www.journalofdairyscience.org/); GVS lab values were also affected by these same factors $(P<0.01$ for all). Again, the significant lab $\times$ sample interaction suggests against simple relative differences in results due to lab. The significant run within lab effect indicates that the analytical results differed from run-to-run within labs. The median value for the difference between the least squares means values between runs within lab was $2.8 \%$ 30-h NDFD, with a range from 0 to $15 \%$ NDFD. Differences among analytical runs within a lab could be due to differences in how the analyses were executed on different days, including variation in ruminal fluid. The PInc 30-h NDFD values were smaller than GVS values $(P<0.05)$, with average differences between methods of 12.0, 25.1, and 15.2\% NDFD for alfalfa, corn forage, and grass forage types, respectively. The average 30-h NDFD values for GVS labs ranged from 44.5 to $53.2 \%$ with no apparent separation of with-ash or ash-free methods. Standard deviations differed among labs and by run within lab, but were not affected by sample or lab $\times$ sample interaction. The differences among labs in standard deviations likely speak to factors inherent in a chosen protocol and how methods are executed within a lab that may increase or decrease analytical variation. We detected no differences between GVS and PInc methods in variability of the results when assessed as standard deviations. This is in contrast to results that reported PInc to have less analytical variability than GVS when alfalfa was used as the substrate and sums 
Table 4. Least squares means results of NDF and fiber fermentability analyses, and numeric differences between values that differ based on results of Bonferroni mean separation for 2 methods (GVS and PInc) used by laboratories (lab) 1 to $11^{1}$

\begin{tabular}{|c|c|c|c|c|c|c|c|c|c|c|c|c|c|c|}
\hline \multirow[b]{2}{*}{ Variable } & \multirow{2}{*}{ 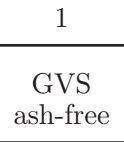 } & \multirow{2}{*}{ 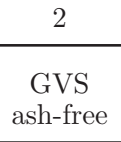 } & \multirow{2}{*}{ 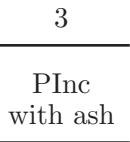 } & \multirow{2}{*}{ 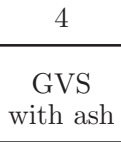 } & \multirow{2}{*}{ 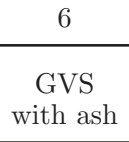 } & \multirow{2}{*}{ 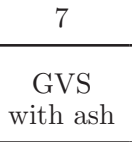 } & \multirow{2}{*}{ 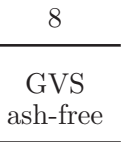 } & \multirow{2}{*}{ 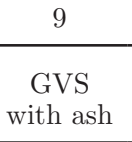 } & \multirow{2}{*}{ 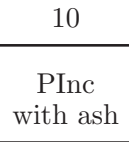 } & \multirow{2}{*}{ 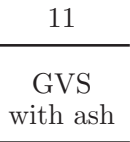 } & \multicolumn{4}{|c|}{$P$-values } \\
\hline & & & & & & & & & & & Lab & $\begin{array}{c}\text { Run } \\
\text { within lab }\end{array}$ & Sample & $\begin{array}{l}\text { Lab } \times \\
\text { sample }\end{array}$ \\
\hline $\begin{array}{l}\text { Fermentation runs, no. } \\
\text { Means of sample replicates }\end{array}$ & 3 & 3 & 3 & 3 & 2 & 3 & 2 & 2 & 3 & 2 & & & & \\
\hline NDF & $47.7^{\mathrm{a}}$ & - & $54.9^{\mathrm{g}}$ & $49.6^{\mathrm{b}}$ & $53.2^{\mathrm{ef}}$ & $52.0^{\mathrm{de}}$ & $54.5^{\mathrm{fg}}$ & $51.1^{\mathrm{cd}}$ & $46.7^{\mathrm{a}}$ & $50.3^{\mathrm{bc}}$ & $<0.01$ & $<0.01$ & $<0.01$ & $<0.01$ \\
\hline 30-h NDFD, $\%$ of NDF & $48.6^{\mathrm{bc}}$ & $50.1^{\mathrm{b}}$ & $31.8^{\mathrm{e}}$ & $49.2^{\mathrm{bc}}$ & $53.2^{\mathrm{a}}$ & $48.6^{\mathrm{bc}}$ & $46.6^{\mathrm{c}}$ & $49.3^{\mathrm{b}}$ & $29.6^{\mathrm{e}}$ & $44.5^{\mathrm{d}}$ & $<0.01$ & $<0.01$ & $<0.01$ & $<0.01$ \\
\hline 30-h dNDF, \% of DM & $22.4^{\mathrm{d}}$ & $23.0^{\text {de }}$ & $16.8^{\mathrm{b}}$ & $23.4^{\mathrm{ef}}$ & $27.4^{\mathrm{h}}$ & $24.4^{\mathrm{g}}$ & $24.4^{\mathrm{g}}$ & $24.2^{\mathrm{fg}}$ & $13.5^{\mathrm{a}}$ & $21.1^{\mathrm{c}}$ & $<0.01$ & $<0.01$ & $<0.01$ & $<0.01$ \\
\hline 48 -h NDFD, $\%$ of NDF & - & - & $45.3^{\mathrm{b}}$ & $53.2^{\mathrm{a}}$ & - & $54.6^{\mathrm{a}}$ & - & $54.8^{\mathrm{a}}$ & $43.5^{\mathrm{b}}$ & $53.9^{\mathrm{a}}$ & $<0.01$ & $<0.01$ & $<0.01$ & $<0.01$ \\
\hline 48-h dNDF, $\%$ of DM & - & - & $24.0^{\mathrm{b}}$ & $25.5^{\mathrm{c}}$ & - & $27.6^{\mathrm{e}}$ & - & $27.2^{\mathrm{de}}$ & $19.7^{\mathrm{a}}$ & $26.2^{\mathrm{cd}}$ & $<0.01$ & $<0.01$ & $<0.01$ & $<0.01$ \\
\hline \multicolumn{15}{|l|}{ SD of sample replicates ${ }^{2,4}$} \\
\hline NDF & $0.45^{\mathrm{ab}}$ & - & $1.54^{\mathrm{c}}$ & $0.53^{\mathrm{ab}}$ & - & $0.56^{\mathrm{ab}}$ & - & $0.17^{\mathrm{a}}$ & $0.77^{\mathrm{b}}$ & - & $<0.01$ & $<0.01$ & 0.22 & $<0.01$ \\
\hline 30-h NDFD, $\%$ of NDF & $1.28^{\mathrm{abc}}$ & $2.16^{\mathrm{bc}}$ & $1.79^{\mathrm{abc}}$ & $2.56^{\mathrm{cd}}$ & - & $1.49^{\mathrm{abc}}$ & $1.26^{\mathrm{abc}}$ & $0.49^{\mathrm{a}}$ & $3.37^{\mathrm{d}}$ & $1.04^{\mathrm{ab}}$ & $<0.01$ & $<0.01$ & 0.59 & 0.89 \\
\hline 30-h dNDF, $\%$ of DM & $0.60^{\mathrm{ab}}$ & $1.14^{\mathrm{bcd}}$ & $0.94^{\mathrm{bcd}}$ & $1.21^{\mathrm{cd}}$ & - & $0.74^{\mathrm{abc}}$ & $0.63^{\mathrm{abc}}$ & $0.24^{\mathrm{a}}$ & $1.46^{\mathrm{d}}$ & $0.56^{\mathrm{abc}}$ & $<0.01$ & $<0.01$ & 0.05 & 0.93 \\
\hline 48-h NDFD, $\%$ of NDF & - & - & $2.08^{\mathrm{cd}}$ & $1.92^{\text {bcd }}$ & - & $0.95^{\mathrm{ab}}$ & - & $0.58^{\mathrm{a}}$ & $2.70^{\mathrm{d}}$ & $1.14^{\mathrm{abc}}$ & $<0.01$ & $<0.01$ & 0.49 & 0.25 \\
\hline 48-h dNDF, $\%$ of DM & - & - & $1.10^{\mathrm{c}}$ & $0.93^{\mathrm{bc}}$ & - & $0.47^{\mathrm{ab}}$ & - & $0.30^{\mathrm{a}}$ & $1.15^{\mathrm{c}}$ & $0.57^{\mathrm{abc}}$ & $<0.01$ & $<0.01$ & 0.55 & 0.83 \\
\hline \multicolumn{15}{|l|}{$\begin{array}{l}\text { Numeric differences }{ }^{5} \\
\text { NDFD }\end{array}$} \\
\hline $30 \mathrm{~h}$ & 5.0 & 6.3 & 10.9 & 15.4 & 25.0 & 6.8 & 9.2 & 5.8 & 14.9 & 26.6 & & & & \\
\hline $48 \mathrm{~h}$ & - & - & 14.4 & 13.8 & - & 5.0 & - & 6.5 & 16.1 & 12.5 & & & & \\
\hline $\mathrm{dNDF}$ & & & & & & & & & & & & & & \\
\hline $30 \mathrm{~h}$ & 3.4 & 4.1 & 7.8 & 7.1 & 16.1 & 3.3 & 6.8 & 3.4 & 7.1 & 18.2 & & & & \\
\hline $48 \mathrm{~h}$ & - & - & 10.1 & 5.9 & - & 2.5 & - & 3.4 & 9.1 & 7.8 & & & & \\
\hline
\end{tabular}

${ }^{\mathrm{a}-\mathrm{h}} \mathrm{In}$ rows, values with different superscripts differ, $P<0.05$.

${ }^{1}$ GVS = Goering and Van Soest (1970) medium; PInc = using preincubated inoculum (Goeser et al., 2009; Goeser and Combs, 2009); "ash-free" or "with ash" describe the basis on which NDF results were expressed.

${ }^{2} \mathrm{NDFD}=\mathrm{NDF}$ digestibility values (fermented NDF as $\%$ of sample NDF); dNDF $=$ fermented NDF as a $\%$ of sample DM.

${ }^{3} \mathrm{SE}$ of the difference (SED) of means: NDF $=0.42 ; 30$-h NDFD $=0.82 ; 30-\mathrm{h}$ dNDF $=0.49 ; 48-\mathrm{h}$ NDFD $=0.88 ;$ and $48-\mathrm{h}$ dNDF $=0.50$.

${ }^{4} \mathrm{SED}$ of standard deviations: NDF $=0.14 ; 30$-h NDFD $=0.40 ; 30-\mathrm{h}$ dNDF $=0.0 .39 ; 48$-h NDFD $=0.37 ;$ and $48-\mathrm{h}$ dNDF $=0.19$

${ }^{5}$ Values represent the minimum numeric difference in analytical measurements between samples declared different using Bonferroni mean separation, $P<0.05$. 
of squares of repeated assays were evaluated (Goeser and Combs, 2009).

The evaluation of analytical precision of GVS 30-h NDFD values reflected the variability that could be expected of an empirical bioassay with multiple steps and differing procedures (Table 5). The average $95 \%$ probability limit for repeatability was $10.2 \%$ NDFD, meaning that actual analytical values in a given lab for a sample that averaged 50\% NDFD would likely fall within the range of approximately 45 to $55 \%$ NDFD. For comparison, the within-lab repeatability range calculated from individual lab SD (as $2 \times \mathrm{SD} \times 2.8$ $=95 \%$ probability range) were 2.7 to $14.3 \%$ with a median value of $7.2 \% 30$-h NDFD; estimated precision based on the standard deviation does vary with lab. The average $95 \%$ repeatability probability limits by forage type were 9.1, 11.4, and 9.9\% 30-h NDFD for alfalfa, corn forage, and grass, respectively; corn forage tended to differ from grass and alfalfa $(P=0.14)$, but alfalfa and grass did not differ $(P=0.57)$. The $95 \%$ probability limit for reproducibility among laboratories was numerically larger (13.4\% 30-h NDFD) than the value for repeatability within lab. This supports a practice commonly followed by field nutritionists of using a single laboratory in an effort to obtain more consistent values. The average $95 \%$ reproducibility probability limits were 10.2, 14.4, and 14.9\% NDFD for alfalfa, corn forage, and grass (corn forage vs. grass and alfalfa, $P=0.20 ;$ grass vs. alfalfa, $P=0.01$ ).

The precision of the $30-\mathrm{h}$ NDFD analytical values affected the ability to detect differences among samples (Figure 1). The bars at the bottom of the figure show the results of mean separation for all data from labs using GVS methods. Samples sharing a common line did not differ $(P>0.05)$. The average maximum difference between samples that were not declared different was 4.4\% 30-h NDFD. Within individual labs, the minimum numeric differences between 30 -h NDFD values that were declared to be different varied from 5.0 to $26.6 \%$ NDFD (Table 4). The detectable difference values did not strictly follow the pattern of sample replicate standard deviations, suggesting that other factors, including differences in mean sample values among runs, may be involved. At its smallest value $(5.0 \%)$, these results for detecting differences among samples agree with the precision evaluation, which indicated that 30-h NDFD values for a sample would likely fall within $5 \%$ NDFD of the mean. The ability to detect differences between samples will be limited if they share the range in which their analytical values are likely to fall. The results on lab-to-lab variation in numeric values needed to detect differences and the 8 to $16 \%$ NDFD $95 \%$ repeatability probability limits around sample means recommend against applying precision greater than 8 to $10 \%$ 30-h

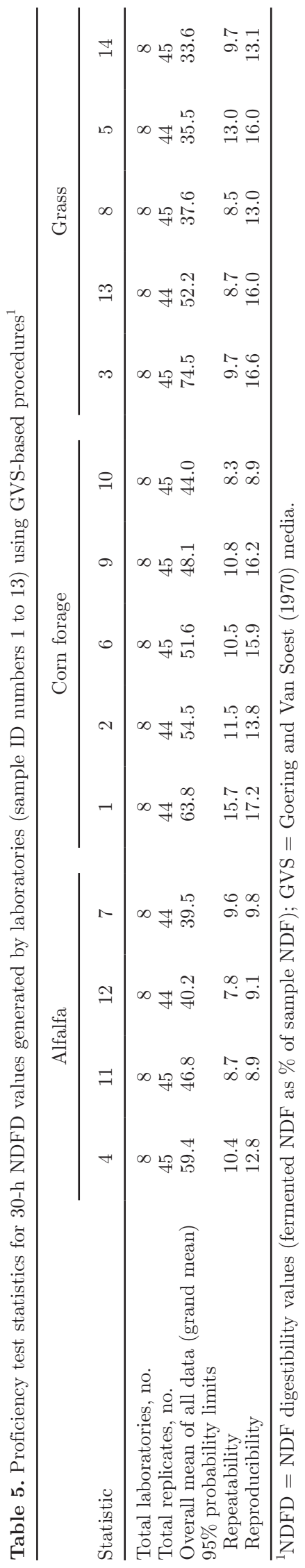

Journal of Dairy Science Vol. 95 No. 4, 2012 


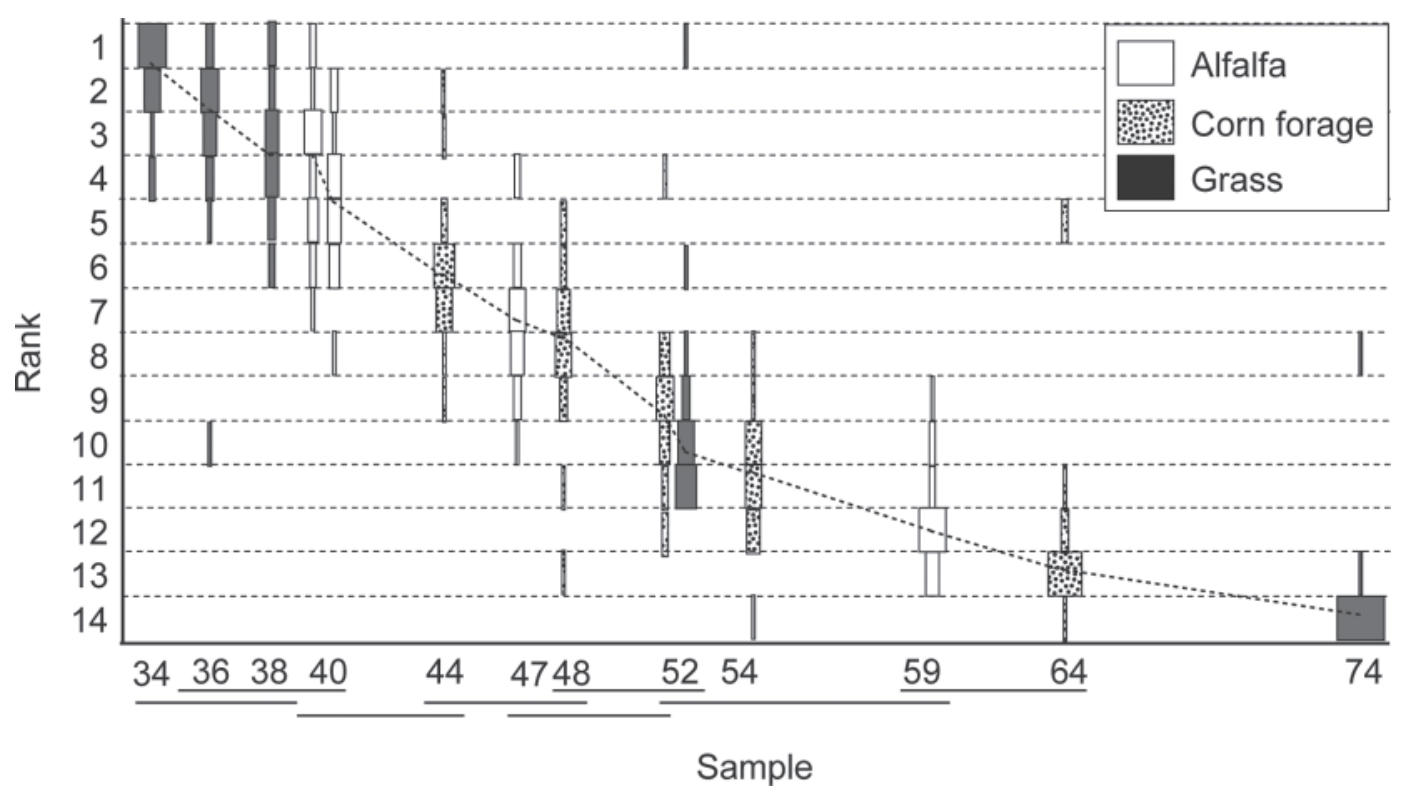

Figure 1. Ranking of all forage samples by 30-h NDF digestibility (NDFD) values (fermented NDF as \% of NDF) as determined by Goering and Van Soest (1970)-related methods for all laboratories and all runs (number of rankings: 279; Spearman correlation coefficient: 0.93). Samples were ranked from least (1) to greatest (14) digestibility within each laboratory in each fermentation run. Each sample is described by a vertical collection of boxes, in which the width of a box is proportional to the percentage of the rankings for that sample from all laboratories in all runs that fell into a given rank. The dashed line is drawn through the median rankings. Samples sharing a common line below the $\mathrm{x}$-axis did not differ in $30-\mathrm{h}$ NDFD value $(P<0.05)$.

NDFD to the data unless improvements can be made in the precision of the assay. Those working with applications in which $30-\mathrm{h}$ NDFD values are used should consider that the precision of outputs should be no greater than what the inputs support.

The question has been raised as to whether use of dNDF (digestible NDF as a percentage of DM) rather than NDFD (digestible NDF as a percentage of NDF) would increase precision and ability to detect differences among samples. A challenge with this comparison is that the measures are derived from the same analytical values and describe related but different things. The dNDF is in the context of digestible DM with no reference to the undigested NDF, and NDFD functions solely in the context of NDF with no reference to the rest of the sample. That said, the use of 30-h dNDF did not reduce the number of factors affecting fermentation results (effects of lab, run within lab, sample, and lab $\times$ sample; Table 4) compared with $30-\mathrm{h}$ NDFD. Standard deviations for sample replicates for 30-h dNDF were affected by lab and run within lab and tended to be affected by sample; the lab $\times$ sample interaction was not significant (Table 4). Standard deviation values for $30-\mathrm{h}$ dNDF are numerically smaller than those of 30-h NDFD, but this difference is based on the mathematical relationship between $\mathrm{dNDF}$ and NDFD: dNDF standard deviation/NDFD standard deviation = sample NDF concentration as a decimal. The sample replicate dNDF standard deviation and means will always be smaller than those of NDFD by a factor of NDF concentration in the sample. The coefficients of variation for 30-h NDFD and dNDF did not differ $(P$ $=0.34$ ), and the mean difference between the measures was not appreciably different from zero $\left(-4 \times 10^{-17}\right)$. This would indicate that dNDF does not have an advantage in precision over NDFD.

For 30-h dNDF, the smallest numeric difference between samples declared to be different ranged from 3.4 to $18.2 \%$ dNDF among labs (Table 4). The method that gave the numerically smallest minimum difference values for 30-h NDFD was the GVS variant in which samples were sealed into tubes and shaken continuously with medium and inoculum. Although this method did not have the smallest standard deviation, it is possible that more consistent results were achieved and smaller differences made detectable by ensuring that the substrate was continuously in contact with media and inoculum. In other methods, portions of samples can remain dry or reside on flask walls above the level of the medium, either of which can decrease fiber fermentation.

\section{0-h NDFD Ranking}

Labs using GVS procedures showed very good ability to rank samples by 30 -h NDFD values (Figure 1, Table 
Table 6. Evaluation of NDF digestibility ranked data for Goering and Van Soest (1970)-related methods ${ }^{1}$

\begin{tabular}{lcccc}
\hline Sample type & Alfalfa & Corn forage & Grass & All samples \\
\hline $\mathrm{N}$ & 79 & 100 & 100 & 279 \\
Spearman correlation coefficient & 0.85 & 0.83 & 0.89 & 0.93 \\
$P$-value & $<0.01$ & $<0.01$ & $<0.01$ & $<0.01$ \\
Rank deviations, $^{2}$ no. $(\%)$ & $57(72)$ & $81(81)$ & $77(76)$ & $113(40)$ \\
0 & $21(27)$ & $13(13)$ & $20(20)$ & $112(40)$ \\
1 & $1(1)$ & $4(4)$ & $4(4)$ & $27(10)$ \\
2 & 0 & $2(2)$ & 0 & $27(10)$ \\
$>2$ & 0 & & 0 & \\
\hline
\end{tabular}

${ }^{1} \mathrm{NDF}$ digestibility values are expressed as fermented NDF as percentage of sample NDF; outliers determined by the Dixon Q test (Dean and Dixon, 1951; Rorabacher, 1991) were omitted from the analysis.

${ }^{2}$ The number (\% in parentheses) of total rankings in which the ranking by laboratories and the average ranking were the same (rank deviation $=0$ ), or differed by 1,2 , or more than 2 rankings (rank deviations $=1,2$, and $>2$, respectively).

6). The overall Spearman correlation coefficient was quite high. The correlation coefficients for corn forage and alfalfa forage types were numerically smaller, but this may be due to the narrower range of 30-h NDFD values for these forages than for grass and all samples together. Of note was the large proportion of ranks across all samples that were the same as the average ranking $(40 \%)$ or were off by one rank (40\%). Even when samples were less than 5\% NDFD apart, they were generally ranked in the correct order.

The capability of labs to reliably rank 30-h NDFD values in a relative context offers the possibility of using this approach to generate more stable and accurate comparisons of NDFD values within and across labs. Numeric analytical values of samples as presently reported for NDFD imply a more precise comparison of samples than is actually achieved due to variability of the values. Relative ranking can be converted to numeric values that should have no less precision than the currently used values and could reduce the effect of within-and between-lab differences in measurements. The assignment of numeric values could be accomplished if labs reported the measured value for a sample, the full range of 30-h NDFD values measured over time, and the average standard deviation for replicate control samples run in fermentations. Conversion of the full range of 30-h NDFD samples into quartiles or some other degree of division and allocation of test sample measurements within the divisions would give relative rankings to samples compared with all other samples. The control sample standard deviation would describe the variability of the assay in a lab and the confidence that the test sample is assigned to the correct division. Numeric values could be derived by assignment of an NDFD value to each division.

Numeric values allocated to NDFD divisions could be derived from values measured in the lab or determined by users who know the range of values to which their nutritional programs are calibrated. This would allow ranks or divisions from any lab to be used equivalently to estimate numeric NDFD values. A caveat to this approach involves the range of samples analyzed by any given lab. Ranking of samples will not be equivalent among labs if the range of sample values varies drastically among labs. Reports from labs of the types and NDFD values of samples run would be useful to assess the likely range of values within a lab. Alternatively, provision of samples to labs to set the range could achieve greater equivalence in sample ranges among labs. Very different NDFD methods such as PInc and GVS may give roughly equivalent rankings, but more work needs to be done to verify this. Concerns that use of sample ranking would not give NDFD values that are sufficiently precise for nutritional programs are countered by the fact that presently available NDFD values, although found to be useful, are not very precise. No basis exists to assume that the precision of NDFD values measured in this study differs from values that have been in use.

\section{8-h NDFD and dNDF}

As with previous NDF fermentability values, 48-h NDFD and dNDF values for all labs were affected by lab, run within lab, sample, and lab $\times$ sample interaction (Table 4; Supplemental Tables S2 and S4, available online at http://www.journalofdairyscience.org/). As was the case with 30-h NDFD standard deviations, 48-h values for NDFD and dNDF were affected by lab and run within lab, but not by sample or the interaction of lab and sample. Analysis of the GVS labs alone showed differences for the effects of run within lab and sample $(P<0.01$ for both) but only tendencies for the effects of lab $(P=0.08)$ and sample $\times$ lab $(P=0.09)$; dNDF values were affected by all factors $(P<0.01$ for all). The minimum difference in 48 -h values between samples that were declared different ranged from 5.0 to $16.1 \%$ NDFD and from 2.5 to $10.1 \%$ dNDF across 
labs. The 48-h difference values for the PInc labs were numerically greater than the $30-\mathrm{h}$ values for NDFD and dNDF, and the reverse was true for the GVS labs. Assessed across all labs, sample replicate standard deviations were greater for 30 -h than for 48 -h NDFD $(P=$ $0.01)$.

\section{Need for Standardization}

The variation in lab-to-lab and run within lab results within GVS or PInc method type suggests a need for standardization to improve reproducibility and precision of in vitro analyses. The use of ranking to generate numeric values, rather than direct use of analytical values, will help to address the issue of accuracy, but improvement in repeatability and reproducibility of values to enhance precision of sample assessment is still desirable. However, because NDFD is an empirical analysis for which there are no absolute sample values against which to compare lab results, proficiency tests that determine consensus values for labs running the same assay are the best approach for evaluating lab performance. In the present study, 5 of 8 labs using GVS methods did not differ in $30-\mathrm{h}$ NDFD values (Table 4). This suggests that some variation in the analytical protocol may be tolerated. With the number of differing steps and variables such as rumen fluid source and sample grinding involved in these assays, it appears that similar results may be achieved from differing protocols through how the various steps combine to give the outcome. Even just considering the potential effect of inoculum donor diet, it is unlikely that all aspects of the in vitro method can be perfectly standardized across labs scattered across a large geographic area to achieve the conformity of a strictly chemical assay. Institution of proficiency testing to assess the ability of labs to obtain similar values and sample ranking across a broad range of samples would be a good step toward improving agreement among labs and similarity of results provided to consumers of a given in vitro assay. New in vitro methods with the same intended use for the analytical values will have to give results comparable to the existing methodology. In order for labs to decrease variability of results, key control points in the method that affect the variability of results need to be determined. Some of this has been addressed in the literature, but it also needs to be done within labs with the methods as they are practiced, and on a more global scale addressing overall methodology with participation of multiple labs or directed research.

In the present study, PInc and GVS results differed by 17 and $10 \%$ NDFD for 30-h and 48-h analyses, respectively, indicating that these in vitro approaches are not equivalent. In contrast to dealing with variation within a method, differences in results between existing and new procedures require clarification as to how the different results are to be used. Equations in diet formulation or evaluation programs are calibrated to a method used to provide the inputs; the method should be specified by the authors of the equations. Accordingly, results from different methods may be appropriately used in equations designed specifically to utilize them. However, results from different assays that are known to give dissimilar results are not interchangeable as inputs in equations without thorough evaluation of the effect of the change and the correctness of the new output in the overall context in which it will be used.

For example, the truly digestible NDF equation in the dairy NRC (2001) specifies use of a 48-h rumen in vitro assay, which is used in an equation that estimates energy available from the diet at $1 \times$ maintenance. Although a specific assay was not cited, the only commonly used in vitro assays for NDF digestibility in the United States available in 2001 were variants of GVS, indirectly suggesting that the NRC equation uses values generated by a GVS assay to approximate NDFD at $1 \times$ maintenance. The PInc values may be more similar to total-tract digestibility values for NDF fed to lactating dairy cows that are not being fed at maintenance [D. K. Combs (Department of Dairy Science, University of Wisconsin, Madison), personal communication]. Such an estimate could have value in evaluating feeds, but needs to be used in its own appropriate predictive context for application to diet formulation. Determination of the utility of GVS compared with PInc values to predict animal response would be a useful endeavor, but one beyond the scope of the present study.

\section{CONCLUSIONS}

The average within-lab precision of $30 \mathrm{~h}$ NDFD values was \pm 5 percentage units and there was an approximately $\pm 1.5 \%$ NDFD greater variability for values generated across labs for the forages tested. The differences in analytical values and variation among labs are likely related to differences in the protocols used and their implementation. Methods that give distinctly different results such as Goering and Van Soest (1970) and Goeser et al. (2009) should be used in contexts appropriate to the procedure. Labs were able to reliably rank forage samples according to 30-h NDFD values. Given the variability in $30-\mathrm{h}$ NDFD values, a relative ranking system for NDFD may be useful to reduce the effect of within- and among-lab variability. Such a system could actually give a more accurate portrayal of the comparative values of samples than current numeric values imply, without necessarily reducing precision below that of the present situation. Further efforts 
are needed to improve the reproducibility among labs and the precision of the analytical results.

\section{ACKNOWLEDGMENTS}

The authors thank Paul Wehling of Medallion Laboratories (Minneapolis, MN) and Chair of the Statistics Committee of AOAC International for assistance in the application of the AOAC International precision evaluation, and Adegbola Adesogan (University of Florida, Gainesville) for providing tropical corn silage and bahiagrass samples. Special thanks go to the participating laboratories that made this study possible.

\section{REFERENCES}

AOAC International. 2002. Interlaboratory collaborative study. Appendix D. Pages 8-9 in Official Methods of Analysis. AOAC International, Gaithersburg, MD.

Bueno, I. C. S., S. L. S. Cabral, S. P. Filho, S. P. Gobbo, H. Louvandini, D. M. S. S. Vitti, and A. L. Abdalla. 2005. Influence of inoculum source in a gas production method. Anim. Feed Sci. Technol. 123-124:95-105.

Damiran, D., T. DelCurto, D. W. Bohnert, and S. L. Findholt. 2008. Comparison of techniques and grinding size to estimate digestibility of forage based ruminant diets. Anim. Feed Sci. Technol. $141: 15-35$

Dean, R. B., and W. J. Dixon. 1951. Simplified statistics for small numbers of observations. Anal. Chem. 23:636-638.

Goering, H. K., and P. J. Van Soest. 1970. Forage Fiber Analysis (Apparatus, Reagents, Procedures and Some Applications). Agric. Handbook No. 379. ARS-USDA, Washington, DC.
Goeser, J. P., and D. K. Combs. 2009. An alternative method to assess 24-h ruminal in vitro neutral detergent fiber digestibility. J. Dairy Sci. 92:3833-3841.

Goeser, J. P., P. C. Hoffman, and D. K. Combs. 2009. Modification of a rumen fluid priming technique for measuring in vitro neutral detergent fiber digestibility. J. Dairy Sci. 92:3842-3848.

Jung, H. G., and V. H. Varel. 1988. Influence of forage type on ruminal bacterial populations and subsequent in vitro fiber digestion. J. Dairy Sci. 71:1526-1535.

Mertens, D. R. 1991. Critical conditions in determining detergent fibers. Pages 5-11 in National Forage Testing Assoc. Forage Analysis Workshop Proc., Milwaukee, WI. National Forage Testing Assoc., Omaha, NE

Mertens, D. R. 2002. Gravimetric determination of amylase-treated neutral detergent fiber in feeds with refluxing in beakers or crucibles: Collaborative study. J. AOAC Int. 85:1217-1240.

NRC. 2001. Nutrient Requirements of Dairy Cattle. 7th rev. ed. Natl. Acad. Sci., Washington, DC.

Oba, M., and M. S. Allen. 1999. Evaluation of the importance of the digestibility of neutral detergent fiber from forage: Effects on dry matter intake and milk yield of dairy cows. J. Dairy Sci. $82: 589-596$

Rorabacher, D. B. 1991. Statistical treatment for rejection of deviant values: Critical values of Dixon's " $Q$ " parameter and related subrange ratios at the 95\% confidence level. Anal. Chem. 63:141-146.

Soder, K. J. 2005. Technical note: Influence of rumen inoculum source on in vitro dry matter digestibility of pasture. Prof. Anim. Sci. 21:45-49.

Tilley, J. M. A., and R. A. Terry. 1963. A two-stage technique for the in vitro digestion of forage crops. J. Br. Grassl. Soc. 18:104-111.

Wilman, D., and A. Adesogan. 2000. A comparison of filter bag methods with conventional tube methods of determining the in vitro digestibility of forages. Anim. Feed Sci. Technol. 84:33-47. 